\title{
Insights on Mediterranean Diet from the SUN Cohort: Cardiovascular and Cognitive Health
}

\author{
Justyna Godos ${ }^{1, *(1)}$ and Fabio Galvano ${ }^{2}$ (i) \\ 1 Oasi Research Institute-IRCCS, 94018 Troina, Italy \\ 2 Department of Biomedical and Biotechnological Sciences, University of Catania, 95123 Catania, Italy; \\ fgalvano@unict.it \\ * Correspondence: justyna.godos@gmail.com
}

Received: 25 April 2020; Accepted: 28 April 2020; Published: 8 May 2020

\begin{abstract}
Epidemiological evidence has demonstrated the association between dietary factors and non-communicable diseases. Great attention has been payed to the Mediterranean dietary pattern, given its richness in anti-oxidant and anti-inflammatory molecules. Numerous reports from the SUN (Seguimiento Universidad De Navarra) cohort have shown that higher adherence to the Mediterranean dietary pattern may be inversely associated with mortality, type 2 diabetes and cardiovascular diseases. Likewise, a link with mental health outcomes, such as depressive symptoms, cognitive status and quality of life was also found, suggesting its beneficial effects toward brain health.
\end{abstract}

Keywords: Mediterranean diet; SUN cohort; risk factor; mortality; cardiovascular; cognitive; mental health; depression; quality of life

Non-communicable diseases are the leading causes of premature mortality and disability in developed countries [1,2]. Obesity rates are growing worldwide [3], representing an important metabolic risk factor for non-communicable diseases [4]. Among various behavioural risk factors, dietary risks account for 11 million deaths and 255 million disability-adjusted life years [5]. Based on current international guidelines, causal inference in nutrition science is supported when agreement between intervention and observational studies occurs [6]. Up to today, great efforts have been made to assess the level of evidence for the association between exposure to dietary factors and the risk of non-communicable diseases [7-12], and results suggest that several components characteristic of the Mediterranean dietary pattern may play a role in affecting human health.

The SUN (Seguimiento Universidad De Navarra) study represents one of the main cohorts in the European Mediterranean area aiming to explore the association between dietary factors and non-communicable diseases. It involves individuals aged 20 years and over who have previously graduated from the University of Navarra, as well as from other different Spanish universities; the cohort has adopted an open continuous recruitment of highly educated participants, which is supposed to reduce the potential risk of bias. The project has contributed for over 20 years to evidence on the importance of traditional dietary patterns, such as the Mediterranean diet, as an ideal dietary choice for the prevention of chronic diseases [13]. The article published by Carlos et al. [14] provided an overview of the main findings from the studies published within the context of the SUN cohort: the study showed that better adherence to the Mediterranean diet was significantly associated with a lower risk of all-cause mortality [15], cardiovascular disease (CVD) incidence and mortality [16], and, more recently, a composite outcome including all-cause mortality, CVD and type-2 diabetes [17]. These results may be explained by several findings reported for cardiovascular risk factors, including a decrease in mean systolic and diastolic blood pressure [18], reduction in the risk of developing type-2 diabetes [19] and reduction in weight gain over the follow up period [20]. The recent Prevención con 
Dieta Mediterránea (PREDIMED) study [21] and supporting meta-analyses comprehensively assessing the evidence on the association between adherence to the Mediterranean diet and cardiovascular outcomes in prospective cohort studies [22,23] provided substantially comparable risk estimates of cardiovascular outcomes. Also, the findings on type-2 diabetes and cardiovascular risk factors have been included in meta-analyses of cohort studies [24] and replicated in an experimental setting, confirming the consistent healthy effects of higher adherence to the Mediterranean diet against blood glucose impairment, insulin sensitivity and type-2 diabetes risk [25].

Another line of research investigated within the context of the SUN cohort has been the role of the Mediterranean diet on mental health, including depressive symptoms, cognitive status and quality of life. Higher adherence to the Mediterranean and other healthy dietary patterns has been associated with a lower risk of depression [26]. Similarly, individuals with low and moderate adherence to the Mediterranean diet showed lower scores in cognitive function than subjects with a higher adherence [27]. These results have been consistent with the investigation on quality of life in which higher adherence to the Mediterranean diet was associated with better self-perceived mental health (as a component of quality of life) [28]. The results from the comprehensive evaluation of observational studies showed no significant association between adherence to the Mediterranean diet and risk of depression in cohort studies, but an inverse significant association with odds of depression in cross-sectional studies was reported [29]. Findings on cognitive status from the SUN cohort confirm, at least in part, the results from meta-analyses on Mediterranean diet and cognitive function, which report a significant association between higher adherence to the Mediterranean diet and older adults' episodic memory and global cognition, but not working memory or semantic memory [30]. Similarly, findings from clinical trials provided evidence of a reduced risk of dementia [31], but mostly non-significant results in terms of cognitive functioning and brain morphology [32].

A traditional Mediterranean diet characterized by (i) high intake of plant-derived foods (including fruit, vegetables and legumes); (ii) use of olive oil, nuts and fish as the main sources of fats; (iii) low consumption of meat and processed foods; and (iv) moderate alcohol intake (mostly wine) during meals, and is a dietary pattern that provides an ideal content of healthy nutrients (such as poly- and monounsaturated fatty acids) and bioactive components exerting anti-inflammatory and antioxidant properties (such as vitamins and polyphenols) [33], many of which have been reported to modulate molecular pathways and play a role in CVD [34] and mental disorder prevention [35]. Thus, conclusions regarding the prevention of cardiovascular diseases and cognitive decline are well supported, while further evidence is needed for other major outcomes.

The contribution of the SUN cohort to nutritional science was crucial in making modern knowledge on the role of certain dietary factors, among which the Mediterranean diet is the core research question of this cohort, in human health. The results obtained are in line with those reviewed in two umbrella reviews of meta-analyses of the role of the Mediterranean diet in preventing non-communicable diseases [36,37]. The data provided is valuable, as a recent overview of literature showed a global decrease in adherence to the Mediterranean diet [38,39], while some surveys based in countries traditionally characterized by this dietary pattern (i.e., Italy and Greece) showed a nutrition transition process and a slow desertion of a Mediterranean-type dietary pattern in favour of more "Westernized" diets, rich in (ultra)processed foods, trans-fatty acids, refined cereals and added sugars [40-42]. Lately, higher adherence to the Mediterranean dietary pattern has been also proven to be a sustainable choice for the environment, as reported by the SUN and other Mediterranean cohorts [43-45]. However, as for all other prospective cohort studies, the SUN cohort shares similar limitations that should be taken into account when considering its results: recall bias, over- or under-estimation of food intake, reverse causation and confounding variables due to the clustering of healthy/unhealthy lifestyle habits are common limitations that cannot be overcome with an observational study design. Nonetheless, the findings from the SUN cohort obtained up until now have been ground-breaking in leading the way toward a better understanding of the role of the Mediterranean diet on human health. The future application of modern epidemiological approaches investigating genetic variants, 
gut microbiota, big data measurement and analysis will help to disentangle aspects related to the Mediterranean diet.

Funding: This research received no external funding.

Conflicts of Interest: The authors declare no conflict of interest.

\section{References}

1. GBD 2017 Disease and Injury Incidence and Prevalence Collaborators Global, regional, and national incidence, prevalence, and years lived with disability for 354 diseases and injuries for 195 countries and territories, 1990-2017: A systematic analysis for the Global Burden of Disease Study 2017. Lancet 2018, 392, 1789-1858. [CrossRef]

2. GBD Global, regional, and national age-sex-specific mortality for 282 causes of death in 195 countries and territories, 1980-2017: A systematic analysis for the Global Burden of Disease Study 2017. Lancet 2018, 392, 1736-1788. [CrossRef]

3. NCD Risk Factor Collaboration (NCD-RisC) Worldwide trends in body-mass index, underweight, overweight, and obesity from 1975 to 2016: A pooled analysis of 2416 population-based measurement studies in 128.9 million children, adolescents, and adults. Lancet 2017, 390, 2627-2642. [CrossRef]

4. GBD 2017 Risk Factor Collaborators Global, regional, and national comparative risk assessment of 84 behavioural, environmental and occupational, and metabolic risks or clusters of risks for 195 countries and territories, 1990-2017: A systematic analysis for the Global Burden of Disease Study 2017. Lancet 2018, 392, 1923-1994. [CrossRef]

5. GBD 2017 Diet Collaborators Health effects of dietary risks in 195 countries, 1990-2017: A systematic analysis for the Global Burden of Disease Study 2017. Lancet 2019, 393, 1958-1972. [CrossRef]

6. National Academies of Sciences, Engineering, and Medicine; Health and Medicine Division; Food and Nutrition Board; Committee on the Development of Guiding Principles for the Inclusion of Chronic Disease Endpoints in Future Dietary Reference Intakes. Guiding Principles for Developing Dietary Reference Intakes Based on Chronic Disease; The National Academies Collection: Reports funded by National Institutes of Health; Oria, M.P., Kumanyika, S., Eds.; National Academies Press (US): Washington, DC, USA, 2017; ISBN 0309462568.

7. Angelino, D.; Godos, J.; Ghelfi, F.; Tieri, M.; Titta, L.; Lafranconi, A.; Marventano, S.; Alonzo, E.; Gambera, A.; Sciacca, S.; et al. Fruit and vegetable consumption and health outcomes: An umbrella review of observational studies. Int. J. Food Sci. Nutr. 2019, 70, 652-667. [CrossRef]

8. Marventano, S.; Godos, J.; Tieri, M.; Ghelfi, F.; Titta, L.; Lafranconi, A.; Gambera, A.; Alonzo, E.; Sciacca, S.; Buscemi, S.; et al. Egg consumption and human health: An umbrella review of observational studies. Int. J. Food Sci. Nutr. 2019, 1-7. [CrossRef]

9. Godos, J.; Tieri, M.; Ghelfi, F.; Titta, L.; Marventano, S.; Lafranconi, A.; Gambera, A.; Alonzo, E.; Sciacca, S.; Buscemi, S.; et al. Dairy foods and health: An umbrella review of observational studies. Int. J. Food Sci. Nutr. 2020, 71, 138-151. [CrossRef]

10. Veronese, N.; Solmi, M.; Caruso, M.G.; Giannelli, G.; Osella, A.R.; Evangelou, E.; Maggi, S.; Fontana, L.; Stubbs, B.; Tzoulaki, I. Dietary fiber and health outcomes: An umbrella review of systematic reviews and meta-analyses. Am. J. Clin. Nutr. 2018, 107, 436-444. [CrossRef]

11. Schwingshackl, L.; Hoffmann, G.; Missbach, B.; Stelmach-Mardas, M.; Boeing, H. An umbrella review of nuts intake and risk of cardiovascular disease. Curr. Pharm. Des. 2017, 23, 1016-1027. [CrossRef]

12. Tieri, M.; Ghelfi, F.; Vitale, M.; Vetrani, C.; Marventano, S.; Lafranconi, A.; Godos, J.; Titta, L.; Gambera, A.; Alonzo, E.; et al. Whole grain consumption and human health: An umbrella review of observational studies. Int. J. Food Sci. Nutr. 2020, 1-10. [CrossRef]

13. Real, H.; Queiroz, J.; Graça, P. Mediterranean food pattern vs. Mediterranean diet: A necessary approach? Int. J. Food Sci. Nutr. 2020, 71, 1-12. [CrossRef] [PubMed]

14. Carlos, S.; De La Fuente-Arrillaga, C.; Bes-Rastrollo, M.; Razquin, C.; Rico-Campà, A.; Martínez-González, M.A.; Ruiz-Canela, M. Mediterranean diet and health outcomes in the SUN cohort. Nutrients 2018, 10, 439. [CrossRef] 
15. Alvarez-Alvarez, I.; Zazpe, I.; Pérez de Rojas, J.; Bes-Rastrollo, M.; Ruiz-Canela, M.; Fernandez-Montero, A.; Hidalgo-Santamaría, M.; Martínez-González, M.A. Mediterranean diet, physical activity and their combined effect on all-cause mortality: The Seguimiento Universidad de Navarra (SUN) cohort. Prev. Med. 2018, 106, 45-52. [CrossRef] [PubMed]

16. Martínez-González, M.A.; García-López, M.; Bes-Rastrollo, M.; Toledo, E.; Martínez-Lapiscina, E.H.; Delgado-Rodriguez, M.; Vazquez, Z.; Benito, S.; Beunza, J.J. Mediterranean diet and the incidence of cardiovascular disease: A Spanish cohort. Nutr. Metab. Cardiovasc. Dis. 2011, 21, 237-244. [CrossRef] [PubMed]

17. Domínguez, L.J.; Bes-Rastrollo, M.; de la Fuente-Arrillaga, C.; Toledo, E.; Beunza, J.J.; Barbagallo, M.; Martínez-González, M.A. Similar prediction of total mortality, diabetes incidence and cardiovascular events using relative- and absolute-component Mediterranean diet score: The SUN cohort. Nutr. Metab. Cardiovasc. Dis. 2013, 23, 451-458. [CrossRef]

18. Núñez-Córdoba, J.M.; Valencia-Serrano, F.; Toledo, E.; Alonso, A.; Martínez-González, M.A. The Mediterranean diet and incidence of hypertension: The Seguimiento Universidad de Navarra (SUN) Study. Am. J. Epidemiol. 2009, 169, 339-346. [CrossRef]

19. Eguaras, S.; Bes-Rastrollo, M.; Ruiz-Canela, M.; Carlos, S.; de la Rosa, P.; Martínez-González, M.A. May the Mediterranean diet attenuate the risk of type 2 diabetes associated with obesity: The Seguimiento Universidad de Navarra (SUN) cohort. Br. J. Nutr. 2017, 117, 1478-1485. [CrossRef]

20. Beunza, J.-J.; Toledo, E.; Hu, F.B.; Bes-Rastrollo, M.; Serrano-Martínez, M.; Sánchez-Villegas, A.; Martínez, J.A.; Martínez-González, M.A. Adherence to the Mediterranean diet, long-term weight change, and incident overweight or obesity: The Seguimiento Universidad de Navarra (SUN) cohort. Am. J. Clin. Nutr. 2010, 92, 1484-1493. [CrossRef]

21. Estruch, R.; Ros, E.; Salas-Salvadó, J.; Covas, M.-I.; Corella, D.; Arós, F.; Gómez-Gracia, E.; Ruiz-Gutiérrez, V.; Fiol, M.; Lapetra, J.; et al. PREDIMED Study Investigators Primary Prevention of Cardiovascular Disease with a Mediterranean Diet Supplemented with Extra-Virgin Olive Oil or Nuts. N. Engl. J. Med. 2018, 378, e34. [CrossRef]

22. Grosso, G.; Marventano, S.; Yang, J.; Micek, A.; Pajak, A.; Scalfi, L.; Galvano, F.; Kales, S.N. A comprehensive meta-analysis on evidence of Mediterranean diet and cardiovascular disease: Are individual components equal? Crit. Rev. Food Sci. Nutr. 2017, 57, 3218-3232. [CrossRef] [PubMed]

23. Rosato, V.; Temple, N.J.; La Vecchia, C.; Castellan, G.; Tavani, A.; Guercio, V. Mediterranean diet and cardiovascular disease: A systematic review and meta-analysis of observational studies. Eur. J. Nutr. 2019, 58, 173-191. [CrossRef] [PubMed]

24. Godos, J.; Zappalà, G.; Bernardini, S.; Giambini, I.; Bes-Rastrollo, M.; Martinez-Gonzalez, M. Adherence to the Mediterranean diet is inversely associated with metabolic syndrome occurrence: A meta-analysis of observational studies. Int. J. Food Sci. Nutr. 2017, 68, 138-148. [CrossRef] [PubMed]

25. Rees, K.; Takeda, A.; Martin, N.; Ellis, L.; Wijesekara, D.; Vepa, A.; Das, A.; Hartley, L.; Stranges, S. Mediterranean-style diet for the primary and secondary prevention of cardiovascular disease. Cochrane Database Syst. Rev. 2019, 3, CD009825. [CrossRef]

26. Sánchez-Villegas, A.; Henríquez-Sánchez, P.; Ruiz-Canela, M.; Lahortiga, F.; Molero, P.; Toledo, E.; Martínez-González, M.A. A longitudinal analysis of diet quality scores and the risk of incident depression in the SUN Project. BMC Med. 2015, 13, 197. [CrossRef]

27. Galbete, C.; Toledo, E.; Toledo, J.B.; Bes-Rastrollo, M.; Buil-Cosiales, P.; Marti, A.; Guillén-Grima, F.; Martínez-González, M.A. Mediterranean diet and cognitive function: The SUN project. J. Nutr. Health Aging 2015, 19, 305-312. [CrossRef]

28. Ruano, C.; Henriquez, P.; Martínez-González, M.Á.; Bes-Rastrollo, M.; Ruiz-Canela, M.; Sánchez-Villegas, A. Empirically derived dietary patterns and health-related quality of life in the SUN project. PLoS ONE 2013,8, e61490. [CrossRef]

29. Shafiei, F.; Salari-Moghaddam, A.; Larijani, B.; Esmaillzadeh, A. Adherence to the Mediterranean diet and risk of depression: A systematic review and updated meta-analysis of observational studies. Nutr. Rev. 2019, 77, 230-239. [CrossRef]

30. Loughrey, D.G.; Lavecchia, S.; Brennan, S.; Lawlor, B.A.; Kelly, M.E. The Impact of the Mediterranean Diet on the Cognitive Functioning of Healthy Older Adults: A Systematic Review and Meta-Analysis. Adv. Nutr. 2017, 8, 571-586. [CrossRef] [PubMed] 
31. Cao, L.; Tan, L.; Wang, H.-F.; Jiang, T.; Zhu, X.-C.; Lu, H.; Tan, M.-S.; Yu, J.-T. Dietary Patterns and Risk of Dementia: A Systematic Review and Meta-Analysis of Cohort Studies. Mol. Neurobiol. 2016, 53, 6144-6154. [CrossRef] [PubMed]

32. Radd-Vagenas, S.; Duffy, S.L.; Naismith, S.L.; Brew, B.J.; Flood, V.M.; Fiatarone Singh, M.A. Effect of the Mediterranean diet on cognition and brain morphology and function: A systematic review of randomized controlled trials. Am. J. Clin. Nutr. 2018, 107, 389-404. [CrossRef]

33. D'Alessandro, A.; De Pergola, G. The Mediterranean Diet: Its definition and evaluation of a priori dietary indexes in primary cardiovascular prevention. Int. J. Food Sci. Nutr. 2018, 69, 647-659. [CrossRef] [PubMed]

34. Mocciaro, G.; Ziauddeen, N.; Godos, J.; Marranzano, M.; Chan, M.-Y.; Ray, S. Does a Mediterranean-type dietary pattern exert a cardio-protective effect outside the Mediterranean region? A review of current evidence. Int. J. Food Sci. Nutr. 2018, 69, 524-535. [CrossRef] [PubMed]

35. Godos, J.; Currenti, W.; Angelino, D.; Mena, P.; Castellano, S.; Caraci, F.; Galvano, F.; Del Rio, D.; Ferri, R.; Grosso, G. Diet and mental health: Review of the recent updates on molecular mechanisms. Antioxidants 2020, 9, 346. [CrossRef] [PubMed]

36. Galbete, C.; Schwingshackl, L.; Schwedhelm, C.; Boeing, H.; Schulze, M.B. Evaluating Mediterranean diet and risk of chronic disease in cohort studies: An umbrella review of meta-analyses. Eur. J. Epidemiol. 2018, 33, 909-931. [CrossRef] [PubMed]

37. Dinu, M.; Pagliai, G.; Casini, A.; Sofi, F. Mediterranean diet and multiple health outcomes: An umbrella review of meta-analyses of observational studies and randomised trials. Eur. J. Clin. Nutr. 2018, 72, 30-43. [CrossRef] [PubMed]

38. Grosso, G.; Galvano, F. Mediterranean diet adherence in children and adolescents in southern European countries. NFS J. 2016, 3, 13-19. [CrossRef]

39. Vilarnau, C.; Stracker, D.M.; Funtikov, A.; da Silva, R.; Estruch, R.; Bach-Faig, A. Worldwide adherence to Mediterranean Diet between 1960 and 2011. Eur. J. Clin. Nutr. 2019, 72, 83-91. [CrossRef]

40. Grosso, G.; Marventano, S.; Giorgianni, G.; Raciti, T.; Galvano, F.; Mistretta, A. Mediterranean diet adherence rates in Sicily, southern Italy. Public Health Nutr. 2014, 17, 2001-2009. [CrossRef]

41. Marventano, S.; Godos, J.; Platania, A.; Galvano, F.; Mistretta, A.; Grosso, G. Mediterranean diet adherence in the Mediterranean healthy eating, aging and lifestyle (MEAL) study cohort. Int. J. Food Sci. Nutr. 2018, 69, 100-107. [CrossRef]

42. Bonaccio, M.; Bes-Rastrollo, M.; de Gaetano, G.; Iacoviello, L. Challenges to the Mediterranean diet at a time of economic crisis. Nutr. Metab. Cardiovasc. Dis. 2016, 26, 1057-1063. [CrossRef] [PubMed]

43. Fresán, U.; Martínez-González, M.A.; Sabaté, J.; Bes-Rastrollo, M. Global sustainability (health, environment and monetary costs) of three dietary patterns: Results from a Spanish cohort (the SUN project). BMJ Open 2019, 9, e021541. [CrossRef]

44. Grosso, G.; Fresán, U.; Bes-Rastrollo, M.; Marventano, S.; Galvano, F. Environmental impact of dietary choices: Role of the mediterranean and other dietary patterns in an italian cohort. Int. J. Environ. Res. Public Health 2020, 17, 1468. [CrossRef] [PubMed]

45. Fresán, U.; Martínez-Gonzalez, M.-A.; Sabaté, J.; Bes-Rastrollo, M. The Mediterranean diet, an environmentally friendly option: Evidence from the Seguimiento Universidad de Navarra (SUN) cohort. Public Health Nutr. 2018, 21, 1573-1582. [CrossRef]

(C) 2020 by the authors. Licensee MDPI, Basel, Switzerland. This article is an open access article distributed under the terms and conditions of the Creative Commons Attribution (CC BY) license (http://creativecommons.org/licenses/by/4.0/). 